\title{
Biochemical and Physiological Characteristics of Fat Cell
}

\author{
Teruo KAWADA $^{1, *}$, Nobuyuki TAKAHASHI ${ }^{2}$ and Tohru FusHIKI ${ }^{1}$ \\ ${ }^{1}$ Laboratory of Nutrition Chemistry, Division of Applied Life Sciences, \\ Graduate School of Agriculture, Kyoto University, \\ Kyoto 606-8502, Japan \\ ${ }^{2}$ Project of Molecular Mechanisms for the Regulation of Energy Metabolism and Adipocyte Functions, \\ Bio-Oriented Technology Research Advancement Institute, \\ Tokyo 105-0001, Japan
}

(Received October 14, 2000)

\begin{abstract}
Summary Since animals are under constant threat of starvation, storage of energy sources inside the body is essential for various activities. Therefore, animals exhibit highly sophisticated mechanisms for storing energy inside their bodies in adipose tissue. However, in humans it has been clarified that fat cell (adipocyte, which comprises adipose tissues) differentiation and the extent of subsequent fat accumulation (hypertrophy of cells) are closely associated with the occurrence and advancement of various diseases resulting from obesity. Moreover, progress in biochemical studies with respect to adipocyte in recent years has rapidly clarified new functions and differentiation mechanisms of adipocytes. Interesting points, in particular, are the function of white adipocytes as "secreting cells" and the molecular mechanism of adipocyte differentiation via the nuclear receptors. Consequently, adipose tissue is being targeted to prevent or treat many common diseases. This paper summarizes recent knowledge on characteristics, differentiation and proliferation of adipocytes and the mechanisms by which adipocytes are regulated.
\end{abstract}

Key Words white and brown adipocytes, adipose tissue, obesity, differentiation, PPAR

\section{WHAT IS AN ADIPOCYTE ?}

Adipocytes include white and brown adipocytes. The term sole adipocyte refers to the former. Both adipocytes develop, differentiate and form into tissues in characteristic parts of organisms. The white adipose tissue has been considered to merely store fat and to be a metabolically inactive tissue. However, recent observations disclose that adipose tissues, including brown adipocyte, possess mechanisms that regulate metabolic pathways that are under the control of the sympathetic nervous system or the endocrine system. It has been clarified that the adipose tissue associated with fat and carbohydrate metabolism is a key to maintaining the energy balance within an entire organism.

\section{The white adipose tissue as an energy store-} house

White adipose tissue, which is the representative adipose tissue, is widely distributed throughout the entire body in large quantities. This white adipose tissue is a specified organ which stores surplus energy in the form of neutral fat after the intake of food and resupplies energy in the form of fatty acid and glycerol when necessary. The minimum requirement for cells to be defined as white adipose is possession of the ability both to synthesize and decompose neutral fat. The white adipose tissue consists of various cell types such as adipocytes in

\footnotetext{
*E-mail: fat@kais.kyoto-u.ac.jp
}

which fat droplets are stored, preadipocytes, fibroblasts, endothelial cells of blood vessels and neurocytes. It was previously believed that among these cells, the number of mature adipocytes increased only during specific developmental stages, that is, during infancy or adolescence; during these stages the lifetime number of adipocytes, approximately 30 billion, is determined. However, recent detailed studies revealed that the number of adipocytes may increase in adults in the case of excessive energy intake or lack of exercise, reaching as much as 40 to 60 billion cells in obese people (1). This number of cells accounts for approximately 0.5 to $1 \%$ of cells comprising the human body. However, the mass of adipocytes accounts for approximately $20 \%$ of the weight of healthy people and even 30 to $40 \%$ of that of obese people. The diameter of adipocytes varies greatly from 10 to $200 \mu \mathrm{m}$. One mature adipocyte normally contains 0.5 to $1 \mu \mathrm{g}$ of fat up to a maximum amount of $4 \mu \mathrm{g}$. In adults with mild obesity, the fat content of each adipocyte increases, resulting in hypertrophy of cells. Hypertrophy of adipocytes has been determined to be closely associated with the occurrence of a disease. Meanwhile, since the size of adipocytes can only increase up to a certain extent, if excessive food is ingested, hyperplasty results and obtained energy is quickly stored without being expended. White adipocytes not only store fat but. also resupply the stored energy in the form of fatty acids to the entire body under the control of the nervous and endocrine 
systems via $\beta_{3}$ adrenergic receptors which maintain an organism's homeostasis.

Since animals are under constant threat of starvation, storage of energy sources inside the body for activities such as capturing prey or escaping from predators is essential for survival. Therefore, animals exhibit highly sophisticated mechanisms for storing energy inside their bodies. Adipose tissues store energy in the form of fat very efficiently via a series of processes such as adipocyte proliferation and differentiation. It is easy to maintain energy inside the body in the form of fat for survival; however, it is difficult to release it. Such physiologically essential characteristics have been closely associated with the development of obesity in humans. Moreover, progress in biological and particularly in biochemical studies with respect to adipocytes in recent years has gradually clarified new functions of adipocytes. An interesting point, in particular, is the function of white adipocytes as "secreting cells" (2). Various chemical factors, including cytokine groups such as the tumor necrosis factor (TNF)- $\alpha$ and leptin are secreted from mature adipocytes filled with fat droplets, and secreted chemical factors strongly influence adipose tissues and the entire body. Physiologically active substances secreted from white adipocytes are called "adipocytokines" (3). It is significant to clarify how factor groups secreted from such adipocytes are related to the occurrence of common diseases such as diabetes, hypertension and arterial sclerosis in the obese. Meanwhile, the benefit of the direct accelerating effect of adipocytes on hair follicle cell differentiation (4), transplant (5) and a technique of augmentation of lost soft tissue in plastic and reconstructive surgery has been reported (6).

2. Brown adipose tissue for energy consumption

The brown adipose tissue has highly developed thermogenic functions. One kilogram of tissue possesses $240 \mathrm{~W}$ of thermogenetic ability (7), which is far more than the basal metabolism of mammals in general, i.e., $4.1 \mathrm{~W}$ per $1 \mathrm{~kg}$ weight. The brown adipose tissue is known to function in the awakening of hibernants or the maintenance of hyperthermia during periods immediately after parturition of animals including humans. Since this tissue is rarely observed macroscopically, its function in humans tends to be questioned, unlike that in experimental animals. However, a series of genes (UCP 2, 3 and 4) similar to the gene encoding the uncoupling protein, $U C P 1$, which is a thermogenetic molecule in brown adipocytes, were recently cloned. Ever since, it is being determined that such new genes are present in abundance in human skeletal muscle. UCP has been of the focus of great interest as a target gene for regulating obesity. Details are discussed in recent publications $(8-10)$.

\section{GENESIS OF ADIPOCYTES}

The term genesis in this section refers to a concept similar to the term development. The term genesis is different from the term of "ontogeny", which indicates a process through which an individual composed of multiple cells is generated from a fertilized egg. The term genesis includes the nuance that what was not previously observed in some parts appears as if an "oncocyte" under a particular period or conditions, but does not merely indicate that what already existed grows. Differential genealogy (origin) of adipocytes and their specificity of physiological function are strongly reflected in the background of the concept of adipocyte genesis. Adipocytes are considered to belong to groups of cells comprising connective tissues and to be differentiated from mescenchymal stem cells. This system of differentiation includes cells such as fibroblasts, chondrocytes, bone cells and smooth muscle cells, which maintain the body's structural framework. The common characteristics of cells in this system are that preadipocytes, widely distributed in the connective tissues, actively proliferate or are fugitive, and that they repair, compensate and rejuvenate existing tissue optimally. However, among the aforementioned cells, adipocytes are specific cells whose tissue formation has no clear delineation. Such characteristics are easily inferred, considering that the hypertrophy and hyperplasia of adipocyte can lead to obesity. The origin of adipocytes is considered a highly significant issue at present when the significance of excessive adipose tissue formation as a predominant cause of various diseases and that of the sections in which adipose tissues are formed are being recognized. Differences in metabolic characteristics depending on cell origin are considered to be closely related to the occurrence of disease. Initial studies with respect to the origin of adipocytes started in the 1870s. Ever since, various theories have been proposed. On the basis of the development of cultured cells and molecular biological procedures in the past 10 years, the following three theories with respect to their origin are dominant (Fig. 1).

\section{Fibroblast theory}

Results of many experiments on cultures of preadipocytes isolated from adipose tissue and on cloning cultured cells such as 3T3-L1 and Ob1771 strongly support the theory that adipose tissues originated from fibroblast (11). Preadipocytes isolated from adipose tissues and cloned cells exhibit characteristics similar to fibroblasts in the stage of the preadipocyte. As differentiation proceeds, expression of genes for lipids, carbohydrates and proteins, and the accumulation of fat droplets, which are characteristics of adipocytes, are observed (Fig. 2). At present, results of studies of genetic control of fibroblast-originated adipocyte differentiation at the transcription level are accumulating. Mechanisms of this theory will be referred to in detail subsequently. The "specific cell theory" states that adipocytes originate from undifferentiated mescenchymal cells with specific potency; this is similar to the fibroblast theory.

\section{Circumvascular primitive organ theory}

At the start of adipocyte formation, primitive tissues (primitive organs) composed of blood capillary nets and mescenchymal cells exist in the connective tissue as 
islets. The primitive organ is linked to an adjacent arteriole and venula via a vessel branch (12). Mescenchymal cells, which include small fat droplets, appear after the primitive organs are formed. As the fetus grows, the accumulation of fat and expression of glycogen granules in the primitive organ are simultaneously observed. The primitive organs are observed in many parts, such as inside the abdominal cavity or

\section{Fibroblast theory}

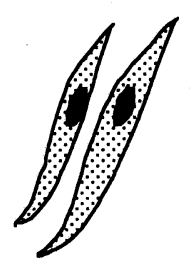

\section{Circumvascular primitive organ theory}

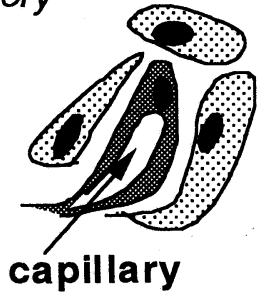

\section{Bone marrow cell theory}

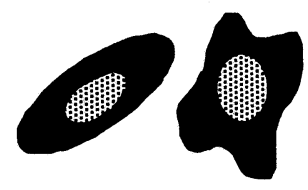

under the skin where adipose tissues are expressed. This has also been widely observed in many vertebrates such as rats or reptiles. Since the primitive organ is formed by the proliferation of vessels made of both endothelial cells and adventitial cells, it is considered a result of blood vessel proliferation. Adipose tissues are already developed and differentiated by the viviparity stage. However, primitive organs are not formed in some adipose tissues, such as those found in the rodent epididymis. In this adipose tissue, fat is accumulated with the formation of capillary blood vessels after birth or the proliferation of mescenchymal cells.

\section{Bone marrow cell theory}

Adipocytes also exist in the bone marrow and are called fatty marrow. Many kinds of cell groups of the hematopoietic system exist in the bone and hematopoietic marrow. It was reported that the origin of adipocytes in the bone marrow is the reticular cells around sino-vessels (13) or monocytes (14). Adipocytes originating from bone marrow cells have been cloned $(15,16)$. Using cloned cultured cells and primary cultured cells from bone marrow (17), the detailed differentiation mechanism is expected to be clarified. Whether or not bone marrow adipocytes could be the origin not only of adipose tissues in the bone marrow but also of those in the peripheral general organs is a highly interesting issue for which clear conclusions have not yet been established. However, the expression of large cells containing fat droplets was observed when healthy people's monocytes in the peripheral blood were cultured in agar (14). Accordingly, there is a high possibility that bone marrow cells are associated with the origin of general adipose tissues. Meanwhile, fatty marrow is believed to be closely associated with the formation of hematopoietic marrow, which should be studied further to clarify new functions of adipocytes.

Fig. 1. Genesis of adipocytes.

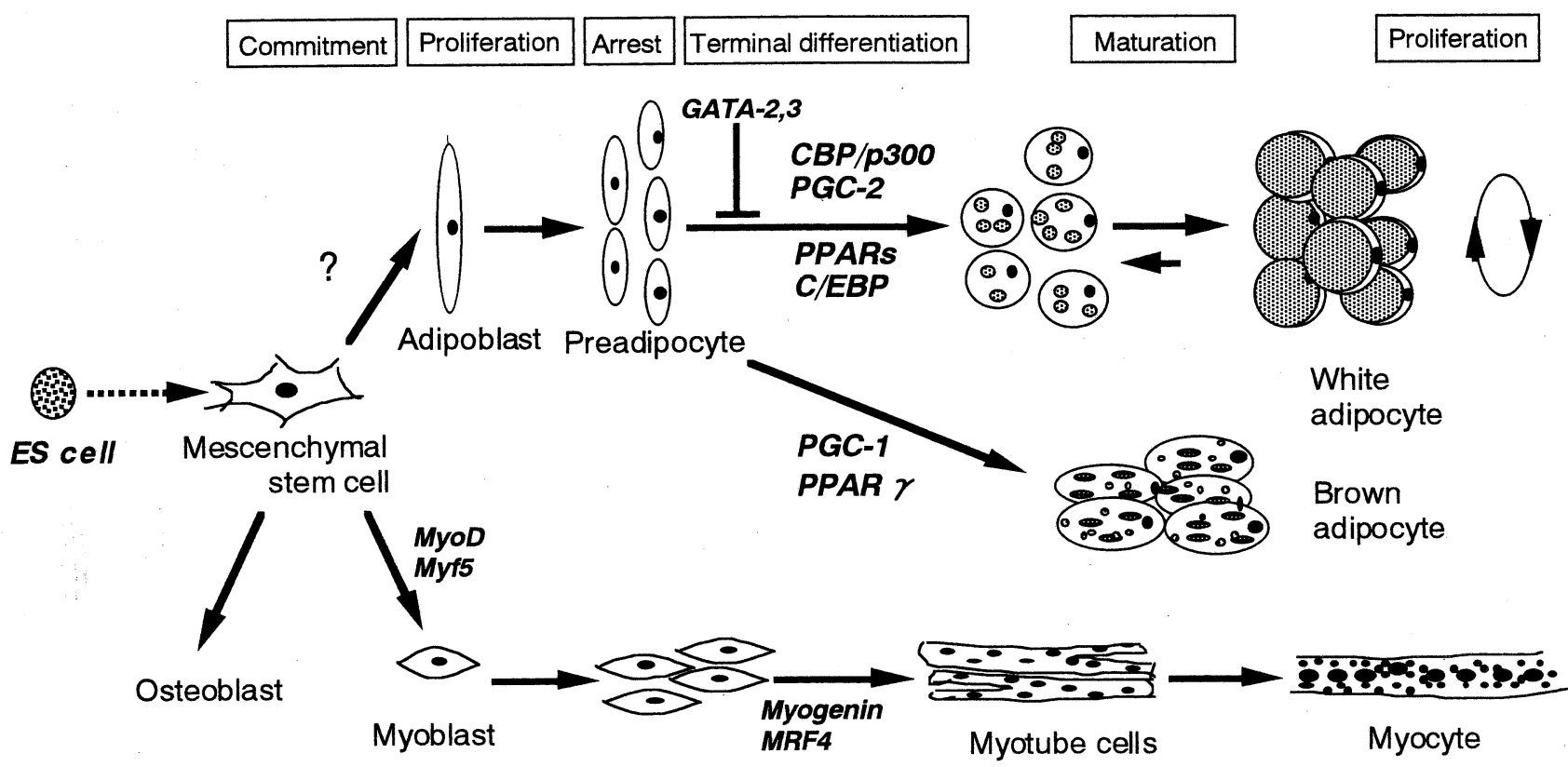

Fig. 2. Genesis and differentiation processes of adipocyte and myocyte from stem cell. 


\section{PROLIFERATION OF ADIPOCYTES}

It has been generally believed that the number of adipocytes is fixed early in life and then remains constant throughout life for both rats (18) and humans (19). In consequence, any expansion of the adipose tissue of adults should only occur through an increase in fat cell size. Since there is an upper limit to cell size, the magnitude of the fat gain would be limited. More careful examination showed that accurate discrimination between the hypertrophic and hyperplastic forms of obesity is difficult, and that mixed types of obesity are frequently observed (20). Then, several recent studies suggested that the number of adipocytes might increase even in adults (21). Bertrand and colleagues reported them to increase in the retroperitoneal deposits throughout most of the life span (22). Furthermore, it was shown that the number of adipocytes increased in adult rats of various strains irrespective of the diet composition (23). Therefore, that the number of adipocytes increases in adults is now accepted as a general concept.

Until now it has been believed that the number of adipocytes increases only at the stage of preadipocyte. However, Sugihara and colleagues recently reported that the proliferation of adipocyte was observed even at a mature stage (24). Interestingly, they observed that four types of mature adipocyte proliferation occurred in a primary cultured system (25), namely, (i) fat droplet division type, (ii) fat droplet holding type, (iii) small fat cell budding type, and (iv) small fat cell budding into cell type. These proliferation types have a future of rapid doubling. Therefore, adipose tissue may physiologically adapt to excessive energy rapid-store.

At the same time, the proliferation of preadipocyte or fibroblast-like adipocyte is strongly dependent on the change of "competent factor" into "progression factor" as protein growth factors (26). We previously reported the presence of a protein factor (preadipocyte growth factor: PAGF) in rat adipose tissue which specifically permits the proliferation of 3T3-L1 and Ob1771 preadipocytes cultured in a completely defined serumfree medium containing only progression factors (epidermal growth factor and insulin) (27). This activity of PAGF was not detected in other cell lines tested, in particular, Swiss 3T3 fibroblast cells, which proliferate in response to a general competent factor such as fibroblast growth factor (FGF). And, the PAGF in fat deposits functions in response to energy intake and contributes to the de novo formation of adipocytes and the growth of adipose tissue (28). PAGF may constitute a useful tool for further elucidation of the relationship between energy storage in adipose tissue and adipose tissue development.

\section{TRANSCRIPTION AND MODIFIED FACTORS ASSOCIATED WITH REGULATION OF ADIPOCYTE DIFFERENTIATION}

Recently, methods of analysis of a master regulator for the expression and regulation of adipocyte differentiation genes have been rapidly developed. Such analy- sis revealed that the CCAAT/enchancer binding protein (C/EBP) family, which is a family of leucine zipper-type transcription factors, and the peroxisome proliferatoractivated receptor (PPAR) family, which is a family of ligand-dependent receptor-type transcription factors, interact with each other, form a network and function as a master regulator (29). $\operatorname{PPAR} \gamma$ and $\mathrm{C} / \mathrm{EBP} \alpha$ are bound to their counterpart genomic promoter region and activate transcription to maintain each other's activity.

\section{C/EBP family}

With respect to the C/EBP family, it was reported for the first time that $\mathrm{C} / \mathrm{EBP} \alpha$ was the dominant candidate as a transcription factor directly associated with adipocyte differentiation. Since the report, four C/EBP subtypes were identified to form a family (30). These subtypes exhibit specific expression patterns before and after adipocyte differentiation and share similar functions. It was clarified that a $\mathrm{C} / \mathrm{EBP}$ response element exists in aP2 (fatty acid binding protein), phosphoenolpyruvate carboxykinase (PEPCK), leptin and even the promoter region of major adipocyte differentiationrelated proteins such as PPAR $\gamma$. The C/EBP and PPAR families function as a master regulator for adipocyte differentiation by forming a network. However, transcription control of adipocyte differentiation by a transcription factor cascade of the aforementioned C/EBP and PPAR families is based on the results of in vitro experiments using cultured cloned cells such as 3T3-L1 preadipocyte. It remains to be clarified whether or not this transcription factor cascade operates in vivo. Lately, Akira et al. produced C/EBP $\beta$ and $\delta$ knockout mice and double knockout mice to study the transcription factor cascade in vivo (31). Their study revealed that PPAR $\gamma$ and C/EBP $\alpha$ were induced in vivo during infancy in the absence of C/EBP $\beta$ and $\delta$. Even if they were induced, a defect in adipocyte differentiation occurs in the absence of C/EBP $\beta$ and $\delta$. Their results suggest the possibility that interactions among master transcription factors for adipocyte differentiation are different between cultured cells and whole animal. Meanwhile, adipocyte differentiation and proliferation occur not only during fetal and infancy stages. Since an adipocyte is a specific cell, which differentiates and proliferates from latent adipoblasts or matured unilocular fat cells in adults (25), there is the possibility that mechanisms regulating differentiation and proliferation differ depending on the stage of genesis of an adipocyte.

\section{PPAR family}

PPARs are the so-called orphan receptors with an unidentified ligand when these were discovered. PPARs also present transcription activation ability induced by compounds such as an anti-hyperlipidemia drug (clofibrate) which has an induction effect on the hepatocyte peroxisome. Since an induction agent was not directly bound to PPAR as its ligand, the term "activated" is attached to the name PPAR. In 1990, the $\alpha$ type was subjected for the first time to cloning from a mouse liver cDNA library (32). Subsequent cDNA cloning experiments identified several PPAR subtype genes from vari- 


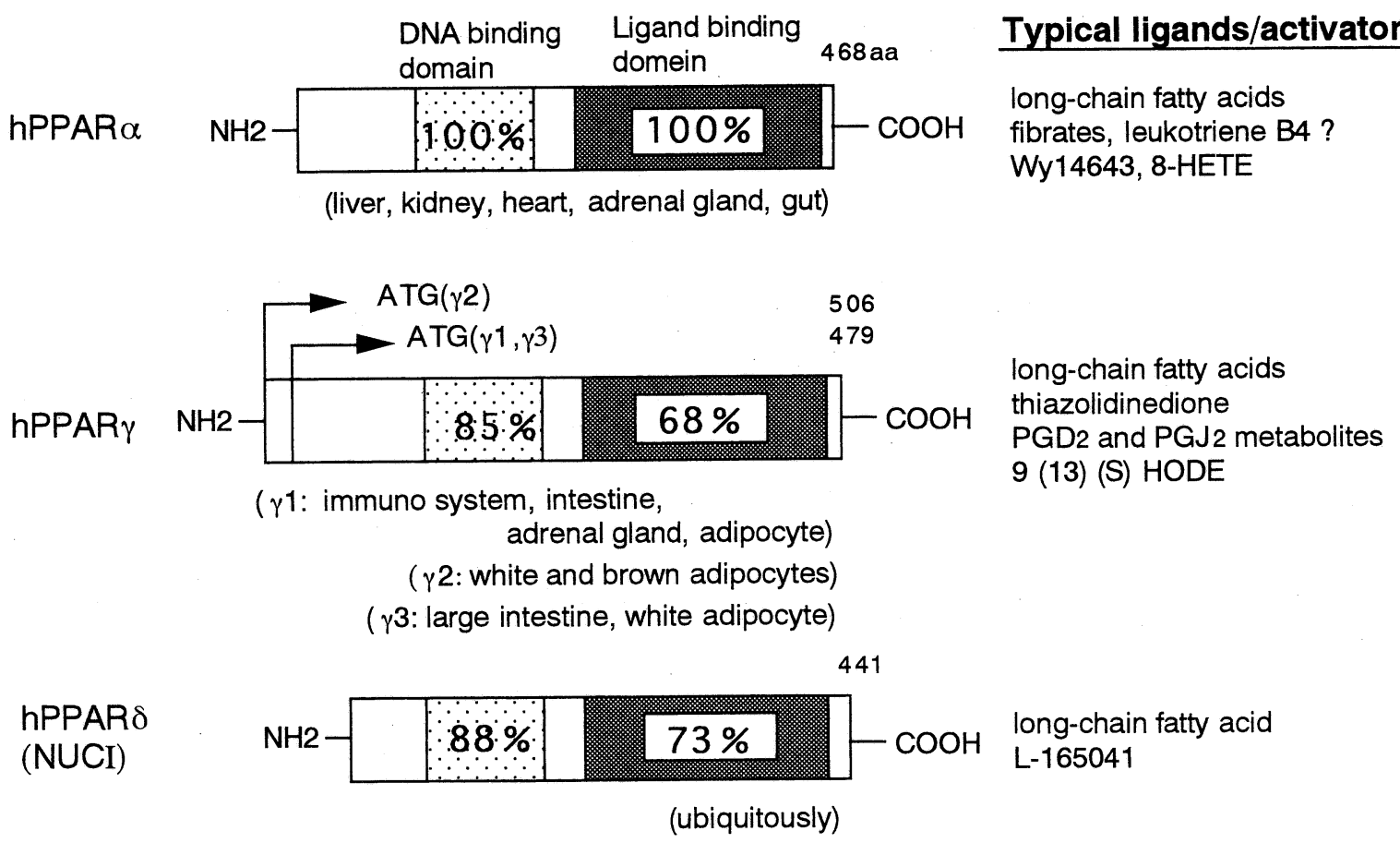

Fig. 3. Biochemical and pharmacological properties of human $\operatorname{PPAR} \alpha, \gamma$ and $\delta$ subtypes.

Table 1. Target genes of PPARs.

\begin{tabular}{|c|c|}
\hline Gene & Function \\
\hline $\begin{array}{l}\text { Lipoprotein lipase }(L P L) \\
\text { Fatty acid translocator }(F A T)\end{array}$ & Fatty acid absorption \\
\hline $\begin{array}{l}\text { Malic enzyme (ME) } \\
\text { Phosphoenolpyruvate carboxykinase (PEPCK) }\end{array}$ & Fatty acid synthesis \\
\hline $\begin{array}{l}\text { Intestinal/liver fatty acid binding protein }(F A B P) \\
\text { aP2/adipose FABP } \\
\text { ApoAI, AII, CIII }\end{array}$ & Fatty acid/lipids transport \\
\hline $\begin{array}{l}\text { Acyl-CoA synthetase } \\
\text { Acyl-CoA oxidase } \\
\text { Keto-acyl-CoA thiolase } \\
\text { Enoyl-CoA hydratase/3-hydroxyacyl-CoA dehydrogenase }\end{array}$ & $\beta$-Oxidation \\
\hline Mitochondrial 3-hydroxy-3-methylglutaryl CoA synthetase & Ketone body production \\
\hline Cytochrom P450CYP $4 A 1$, CYP $4 A 6$ & $\omega$-Oxidation \\
\hline Leptin (ob gene) & Food intake, Energy metabolism \\
\hline Uncoupling protein $(U C P) 1,2,3$ & Thermogenesis \\
\hline
\end{tabular}

ous animal species and organs. These PPAR subtype genes form a family (Fig. 3). In mammals, three subtype genes, $\alpha, \delta$ [called NUC I in human, fatty acid-activated receptor (FAAR) in mouse, and $\operatorname{PPAR} \beta$ in frog] and $\gamma$, were found. The $\alpha$ type was expressed mainly in the liver, cardiac muscle and digestive tract, while the $\delta$ type was expressed not in specific tissues but in all tissues ubiquitously (33). Meanwhile, the $\gamma$ type is known to consist of two isoforms, the $\gamma 1$ and $\gamma 2$. They are formed from different mRNAs using the $5^{\prime}$ terminal by selecting the promoter of the PPAR $\gamma$ gene. The $\gamma 2$ isoform specifically expressed in adipocytes is closely associated with adipocyte differentiation, which will be dis- cussed subsquently (34). The $\gamma 1$ isoform is expressed in organs of the immune system, adrenal glands and the small intestine. Moreover, in human adipose tissues, existence of a third isoform, the $\gamma 3$ isoform, was suggested, which is an interesting point (35). Similar to nuclear receptors such as the retinoic acid receptor (RAR), the thyroid hormone receptor (TR) and the vitamin D receptor (VDR), each PPAR forms a stable heterodimer with the retinoide $\mathrm{x}$ receptor ( $\mathrm{RXR}$ ), whose ligand is 9cis retinoic acid. Each PPAR is then bound to a specific DNA sequence [AGGTCA-X-AGGTCA; peroxisome proliferator response element (PPRE)] of a target gene (36). Table 1 shows representative target genes of PPAR. 
However, genes that control the early stages of adipogenesis remain unknown. Quite recently, it was shown that constitutive GATA-2 and GATA-3 expression suppressed adipocyte differentiation and trapped cells at the preadipocyte stage (37). The GATA family of transcription factors share highly conserved zincfinger DNA binding domains and bind specifically to a consensus DNA sequence (A/T)GATA(A/G) (38).

\section{PPAR's ligand and activation modified fac-} tor

One characteristic of the PPAR family is that the compounds with various chemical structures can accommodate ligands as shown in Fig. 3. The $\alpha$ and $\delta$ types accept the clofibrate group or the fatty acid group as a ligand, while the $\gamma$ type accept thiazolidinedione derivatives, which are discussed subsequently, as ligands. Specificity is observed in ligand binding or activation among PPAR subtypes. Such specificity is also supported by the low homology in the ligand-binding domain among subtypes (Fig. 3). Thiazolidinedione derivatives, which are used to treat diabetes mellitus and improve insulin resistance, are compounds originally developed on the basis of their effect on decreasing blood glucose levels as an index for genetically obese animals. The mechanism of action of thiazolidinedione derivatives was initially unknown. Subsequently, as studies progressed, it became clear that thiazolidinedione derivatives do not only have the effect of decreasing glucose and lipid levels in the blood, but also have a strong effect on inducing adipocyte differentiation $(39,40)$. What is interesting is that, according to some recent reports, thiazolidinedione derivatives and 15-deoxy$\Delta^{12,14}$-prostaglandine $\mathrm{J} 2$, which is a prostaglandin $\mathrm{D}_{2}$ metabolite (Fig. 4), bind directly to PPAR $\gamma$ as a ligand essential for adipocyte differentiation and induce adipocyte differentiation $(41,42)$. However adipocyte differentiation is controlled not only by PPAR $\gamma$ but also $\operatorname{PPAR} \alpha$, which was demonstrated in studies using a specific ligand of PPAR $\alpha$ 's or the arachidonic acid oxide metabolite (8-hydroxy eicosatetoraenoic acid) $(43,44)$. Another interesting point is that the oxidized metabolites of linoleic acid (9- and 13-hydroxy octadecadienoic acid) produced from oxidized LDL were identified as endogenous ligands of $\operatorname{PPAR} \gamma$, and that $\operatorname{PPAR} \gamma$ is also viewed as a key regulator of gene expression in macrophage differentiation and foam cell formation (45). In the future, PPAR will be considered as a significant factor in cardiovascular studies.

Since thiazolidinedione derivatives are substances that strongly promote adipocyte differentiation, we have pointed out that their efficacy as agents to improve insulin resistance is highly dependent on newly developed young adipocytes without insulin resistance (46). Lately, Kadowaki and colleagues initiated a study based on the idea that the development of insulin resistance accompanied with obesity should be attributed to adipose tissues. They suggested a mechanism by which the characteristics of adipocytes were changed (minimization of adipocytes) by promoting adipocyte differentiation induced by thiazolidinedione derivatives via

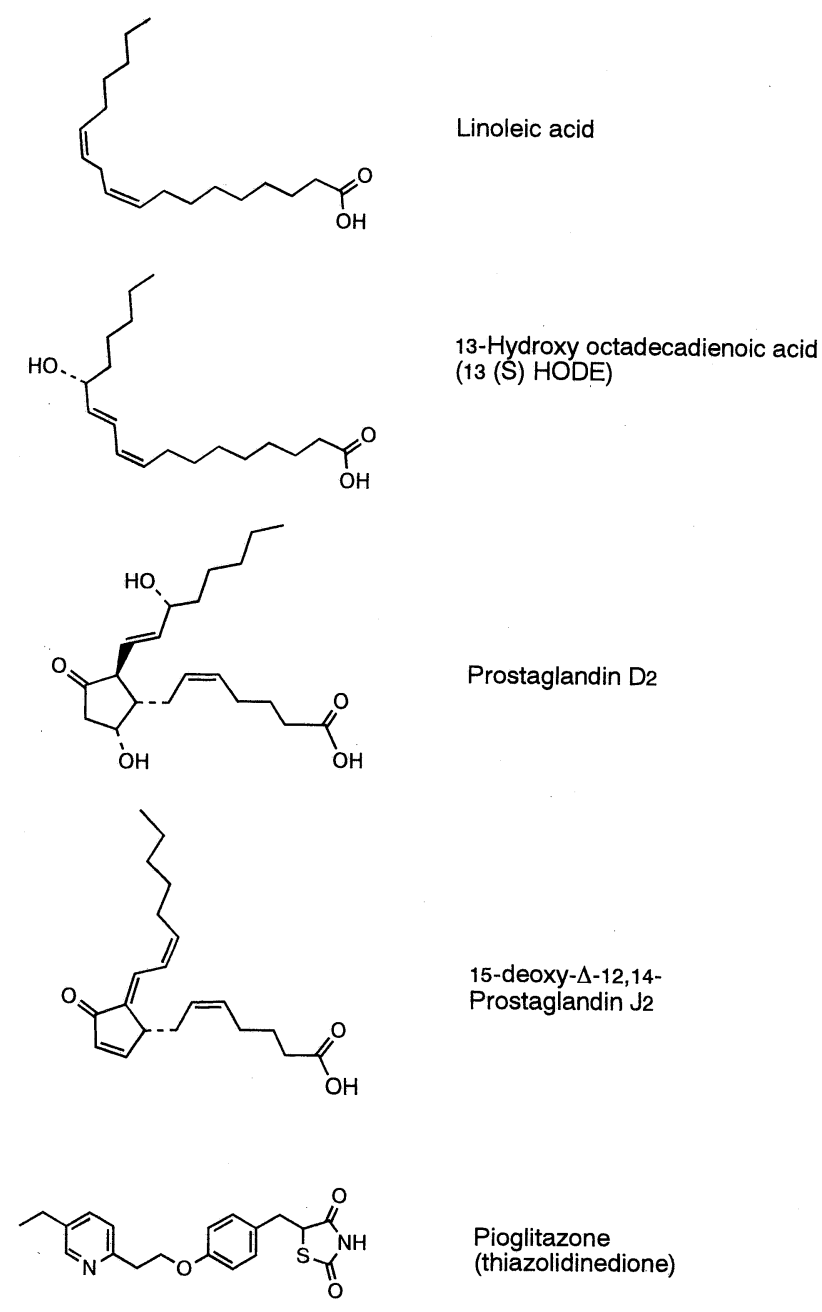

Fig. 4. Structures of natural and synthetic PPAR $\gamma$ ligands.

$\operatorname{PPAR} \gamma$, resulting in improvement of insulin resistance (47). In other words, large adipocytes in the obese state are malignant and secret factors that exacerbate insulin sensitivity, such as TNF $\alpha$, leptin and free fatty acids in large quantity; however, such factors are maintained at normal levels in small benign adipocytes, resulting in the abolition of insulin resistance. As demonstrated in experiments using a PPAR $\gamma$ deficient mouse (48), the mechanism proposed by Kadowaki et al. points out that insulin resistance is improved by changing the characteristics of adipose tissues which are the underlying cause of insulin resistance. With this viewpoint, the underlying mechanism is of great interest. A combination of guided nutrition and diet therapy is significant to prevent re-hypertrophy of adipose tissues by this mechanism.

According to some reports, fatty acids such as linoleic acid, arachidonic acid and eicosapentaenoic acid (EPA) in food directly become ligands for PPAR $\alpha$ and $\delta(49,50)$. They function not only as adipocyte differentiation regulators but also as PPAR molecular sensors in lipid metabolism to play a significant role in continuing the obese state. This interesting finding has been focused on recently in several studies. 


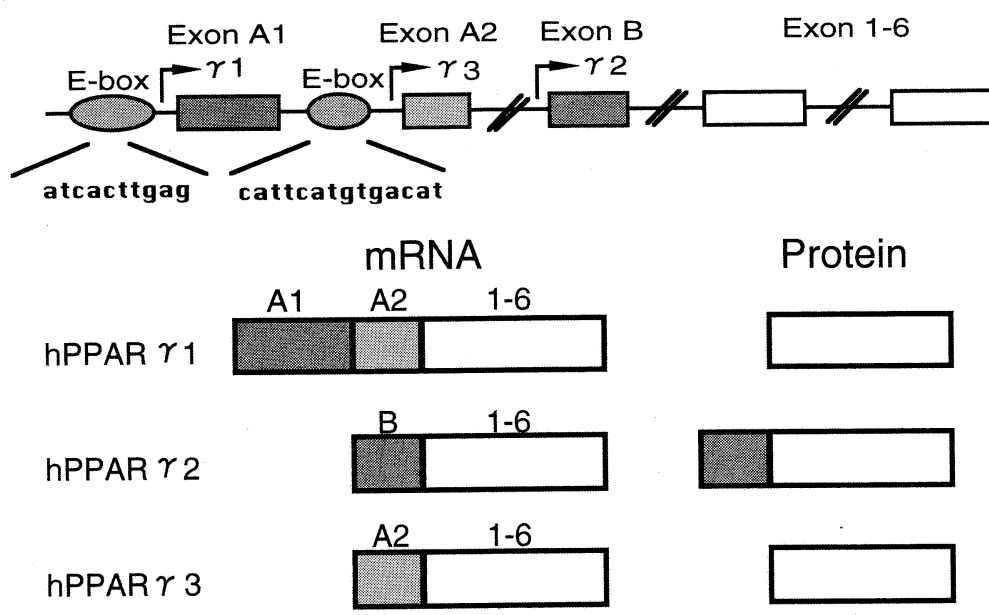

Fig. 5. Structure of human PPAR $\gamma$ gene and the PPAR $\gamma$ mRNA and protein. Noteworthy, the three mRNA species give rise to two different PPAR $\gamma$ proteins (PPAR $\gamma 1$ and 2). E-box, ADD1/SREBP1 binding site.

\section{PPAR activity modified factors}

Studies on nutritional behavior determining the expression of PPAR $\gamma$ revealed that no relationship was observed between the extent of obesity in mice and the intake of fat-enriched food and PPAR $\gamma$ mRNA. The expression of PPAR $\gamma 2$ was reduced by taking vitamins $A$ and D, and the expression of PPAR $\gamma 2$ mRNA was enhanced by insulin $(51,52)$. Vitamins $A$ and $D$ have been shown to affect adipose conversion in vivo and in vitro. We proposed the model of these vitamins as suppressors on adipocyte development through the retinoid/thyroid/vitamin D/PPAR receptors subfamily (53). Furthermore, it is well known that adipocyte differentiation is controlled by cell growth factors. Recently, it was suggested that $\operatorname{PPAR} \gamma$ was phosphorylated and rendered inactive due to a mitogen-activated protein (MAP) kinase that was induced by a growth factor stimulus $(54,55)$. Meanwhile, contrary to the aforementioned reports, dominant negative experiments using MAP kinase kinase (MKK1) revealed that PPAR $\gamma$ phosphorylation by MAP kinase enhanced activation (56). Until recently, activated or inactivated physiological functions resulting from phosphorylation of PPAR $\gamma$ have not been determined. However, only recently, proline adjacent to the 114 th serine, which was the phosphorylated site of human $\operatorname{PPAR} \gamma$, was subjected to missense mutation and transformed into glutamine; Pro115Gln mutation was observed. This mutation was closely related to the occurrence of human obesity (57). Experiments at the cellular level proved that the Pro115Gln-mutated PPAR $\gamma$ actually prevents the 114th serine from being phosphorylated, resulting in nonregulation of adipocyte differentiation. Accordingly, it is assumed that the human PPAR $\gamma$ subjected to phosphorylation due to the aforementioned phosphorylation becomes inactive and maintains adipocyte differentiation at a normal state. Furthermore, some reports state that Pro12Ala mutation results in a high body mass index (BMI) (58), while Pro467Lue and Val290Met mutations result in a normal BMI and strong insulin resistance (59).
5. Transcription factors that control the production of PPAR and its ligand: ADD1/SREBP1C

A transcription factor called adipocyte determination and differentiation-dependent factor 1 (ADD1) was found in adipocytes (60). This factor is assumed to influence adipocyte differentiation by regulating $\operatorname{PPAR} \gamma$ ligand production when adipocyte differentiation occurs (61). ADD1 is the same in function as the sterol regulatory element binding protein (SREBP)1c. SREBP 1c is also a transcription factor performing a significant role in adjusting the metabolism of cholesterol and was cloned by Goldstein and Brown et al. in 1993, during the same period when ADD1 was found. Some reports state that transgenic mice that produce excessive SREBP1 are obese and exhibit excessive insulin resistance as well as abnormality in fat metabolism $(62,63)$. Recent developments in genome analysis of the PPAR $\gamma$ gene revealed that the E-box, which includes SREBP-specific recognition DNA sequences, exists upstream of Exons A1 and A2 (Fig. 5) (35). The regulation of ADD1/SREBP1, PPAR subtypes and isoform expression or their feedback control mechanism are of great interest in studies of the occurrence of various diseases attributed to obesity and malnutrition and of how to improve the treatment of such diseases.

\section{COACTIVATORS ASSOCIATED WITH ADIPOCYTE DIFFERENTIATION}

1. Coactivators associated with white adipocyte differentiation: CBP/p300 and PGC-2

Recently, characteristics of coactivators (integrators) or corepressors, which promote interactions between nuclear receptors and proteins, and control activation of transcription positively or negatively, have been clarified (Fig. 6). Kamei and Rosenfeld et al. in 1993 reported the cAMP response element binding protein (CBP) as a coactivator (integrator) essential for activation of transcription by nuclear receptor (64). CBP exhibits a high similarity with p300, which has the same transcription factor coactivator function, with respect to their amino acid sequence; therefore, CBP is called $\mathrm{CBP} / \mathrm{p} 300$. $\mathrm{CBP}$ is a $265-\mathrm{KD}$ nuclear protein, which is 


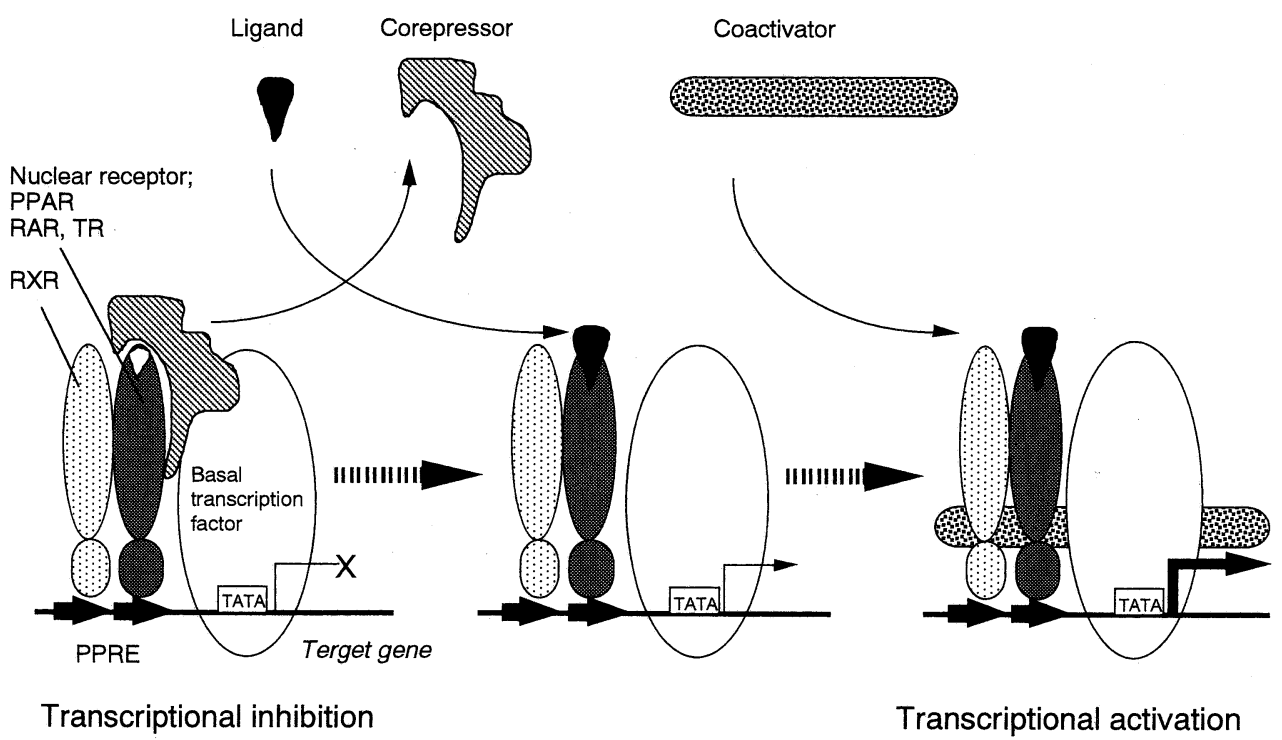

Fig. 6. Transcriptional activation of PPAR on the promoter region of target gene with ligand and coactivator.

Table 2. Adipocyte differentiation factors and transcriptional factors controlled by $\mathrm{CBP} / \mathrm{p} 300$.

Downstream transcriptional factors interacting with $\mathrm{CBP} / \mathrm{p} 300$

\begin{tabular}{l|lll}
\hline & $\begin{array}{l}\text { Long-chain fatty acids } \\
\text { Prostanoids }\end{array}$ & PPAR $\alpha, \delta, \gamma$ \\
& Thiazolidinedione & PPAR $\gamma$ \\
Differentiation promotory factors & Glucocorticoid & Glucocorticoid receptor (GR) \\
& Thyroid hormone & Glucocorticoid receptor (TR) \\
& cAMP & cAMP response element binding protein (CREB) \\
& Insulin & pp90 ${ }^{\text {rsk }}$ \\
\hline \multirow{3}{*}{ Differentiation inhibitory factors } & Vitamin A & Retinoic acid receptor (RAR) \\
& Vitamin D & Vitamin D receptor (VDR) \\
& Phorbol ester & AP-1 \\
& TNF- $\alpha$ & NF- $\kappa$ B \\
& Interferon & STAT1 \\
\hline
\end{tabular}

expressed in small amounts in various tissues or cells, with various functional protein motifs such as $\mathrm{Zn}$ fingers or bromo domains. CBP forms a protein structure with various signal transduction systems such as Jun, Fos, C/EBP $\beta$, PP90 ${ }^{r k}$, NF- $\kappa \mathrm{B}$, MyoD, SRC-1 (p160), histone acetylase and even with STAT as well as nuclear receptors and functions as an integrator. By using a model for formation of a protein complex, synergy and antagonism between nuclear receptors and other transcription factors are possibly explained in a unified manner (65).

Recently, direct evidence of the need for CBP as a coactivator of PPAR $\gamma$ for adipocyte differentiation and the mechanism of action of thiazolidinedione derivatives were reported (66). We found that CBP is already expressed at the stage of preadipocytes prior to $\operatorname{PPAR} \gamma$, in preparation for the differentiation process. Many fac- tors influencing adipocyte differentiation have been reported. Most factors interact with CBP via various transcription factors downstream of the information-transmitting pathway. These interesting findings help to explain the control mechanism by adventitious factors in a unified manner (Table 2). Similar to CBP, SRC-1 (p160) is also a significant coactivator. Since p160 (SRC-1) is more strongly associated with nuclear receptors than $\mathrm{CBP} / \mathrm{p} 300$, p160 (SRC-1) is expected to function in adipocyte differentiation (personal communication with Dr. Yasutomi Kamei). Only recently, Spiegelman et al. reported that PGC-2 (PPAR $\gamma$ coactivator 2) is a PPAR $\gamma$ coactivator associated with white adipocyte differentiation (67). In contrast to CBP/p300, which is associated with the AF-2 domain of PPAR $\gamma$, PGC-2 is associated with the AF-1 domain and reinforces transcription activity. Another interesting char- 


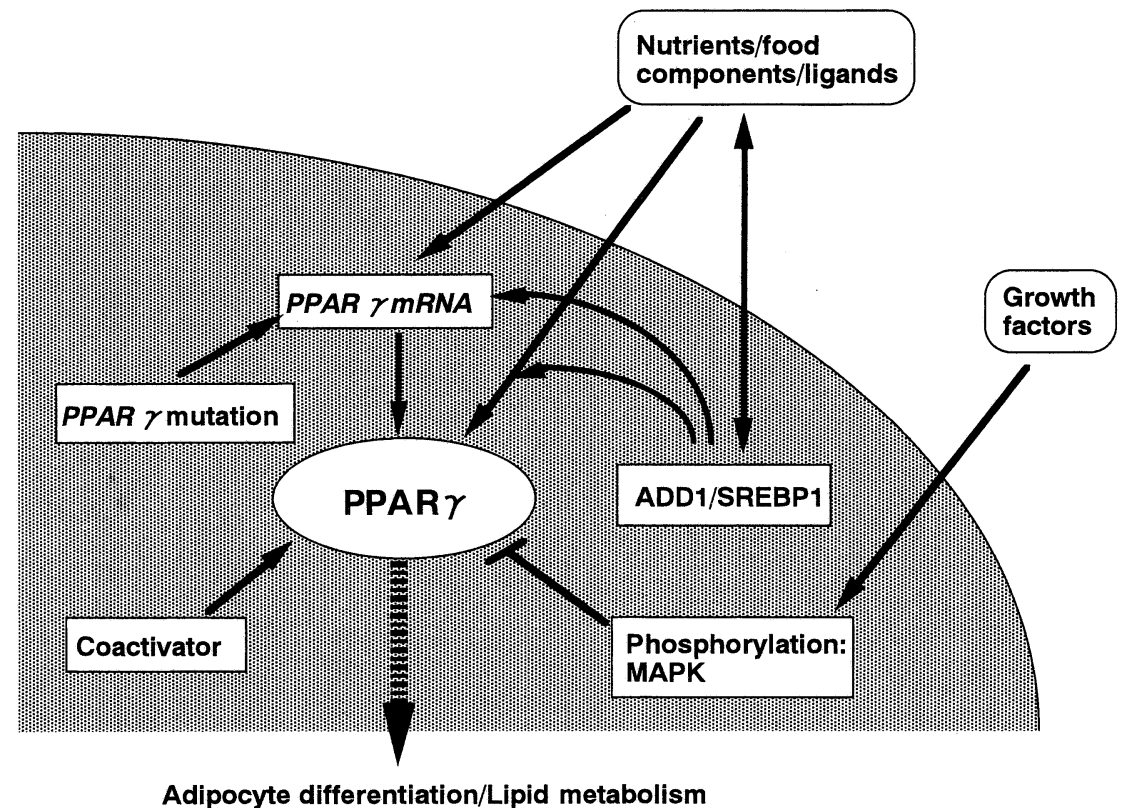

Fig. 7. Effects of PPAR $\gamma$ expression and activation factors on adipocyte differentiation and lipid metabolism. ADD1, adipocyte determination and differentiation-dependent factor 1; SREBP1, sterol regulatory element binding protein 1; MAPK, mitogen-activated protein kinase.

acteristic is that it does not interact with other PPAR subtypes. Interaction between a receptor-subtype-selective coactivator and PPAR $\gamma$ is significant in white adipocytes. Recently, it was reported that natural or synthetic ligand binding might alter PPAR $\gamma$ structure in a ligand-type specific way, resulting in distinct PPAR $\gamma$ coactivator interaction (68). Clarification of such interactions could lead to a breakthrough in the development of new pharmaceuticals.

2. Coactivator associated with brown adipocyte: PGC-1

In 1998, Spiegelman et al. reported that PGC-1 (PPAR $\gamma$ coactivator 1 ) is a PPAR $\gamma$ co-activator associated with brown adipocyte differentiation and mitochondria development (69). PGC-1 functions as a coactivator in association with a basic transcription system; however, it is not homologous with already known coactivators. PCG-1 is neither expressed in white adipocytes, nor involved in the differentiation. It is interesting that PGC-1 not only functions as a coactivator of PPAR $\gamma$ in brown adipocytes for coupling activation but also controls the expression of genes related to energy metabolism of uncoupling protein-1 (UCP-1) and mitochondria. The discovery of PGC-1 helped in the understanding of the genesis and differentiation of brown adipocytes, which had been completely uncertain, and even of that of the mitochondria-rich red or cardiac muscle.

In adipocytes, multiple regulatory mechanisms exist such as the phosphorylation modification of PPAR $\gamma$ protein by the growth factor/MAP kinase system, the control of PPAR $\gamma$ and its ligand production through ADD1/SREBP1c transcription factors, and the transcription activation ability of PPAR $\gamma$ itself due to coactivators such as PGC-1 and 2 (Fig. 7). Through these minute regulations in the PPAR mechanism, a balance among adipocyte proliferation and differentiation, the maturation process and lipid metabolism is well controlled.

\section{CONCLUSIONS AND PERSPECTIVES}

Adipocyte acts as a secreting cell related to the occurrence of common diseases such as diabetes, hypertension and atherosclerosis in obesity. Its differentiation and functional regulations proceed positively or negatively with respect to utilization of stored energy in response to signals (ligands) from within and without the adipose tissue, such as an increase or decrease in intraorganism energy. The framework of the physiological response of the adipose tissue involves a regulatory mechanism by ligand-requiring PPAR and coactivators. Physiologically, nutritional ligands such as fatty acids or their derivative prostanoids should be supplied. As has been pointed out, diseases easily caused by excessive intake of high-energy food, such as type 2 diabetes mellitus, are a result of a breakdown of this system (70). It is obvious that the signal-transmitting network via the PPAR-coactivator system is involved in the regulatory mechanism. Further clarification of this system will lead to the development of new nutritional and diet therapy or of new drugs against common diseases attributed to obesity. And, recently it was shown that embryonic stem cells differentiated into adipocyte in vitro (71) and a brown adiocyte cell line was immortalized from $p 53-k n o c k o u t$ mice (72). In the near future, the function of white adipocyte "secreting cells" and brown adipocyte "metabolic heat production" in combination with genome science may yield some benefit such as cell therapy, tissue engineering and transplant technologies in the field of regenerative medicine. 


\section{Acknowledgements}

We would like to thank Prof. Etsuro Sugimoto (University of Shiga Prefecture) for his kind guidance and continuous encouragement. This work was supported in part by a Grant-in-Aid for Scientific research from the Ministry of Education, Science, Sports and Culture of Japan and by a grant from Bio-Oriented Technology Research Advancement Institute, Japan (PROBRAIN project).

\section{REFERENCES}

1) Bray GA, Bouchard C, James WPT. 1998. Definitions and proposed current classification of obesity. In: Handbook of Obesity (Bray GA, Bouchard C, James WEP, eds), p 31-40. Mercel Dekker, New York.

2) Ailhaud G. 1996. Molecular and cellular determinants of body weight regulation. In: Regulation of Body Weight: Biological and Behavioral Mechanisms (Bouchard C, Bray GA, eds), p 211-222. John Wiley \& Sons, Chichester.

3) Shimomura I, Funahashi T, Takahashi M, Matsuzawa Y. 1996. Enhanced expression of PAI-1 in visceral fat: Possible contributor to vascular disease in obesity. Nat Med 2: 800-803.

4) Misago N, Toda S, Sugihara H, Kohda H, Narisawa Y. 1998. Proliferation and differentiation of organoid hair follicle cells co-cultured with fat cells in collagen gel matrix culture. Br J Dermatol 139: 40-48.

5) Iyama K, Ohzono K, Usuku G. 1979. Electron microscopical studies on the genesis of white adipocytes: Differentiation of immature pericytes into adipocytes in transplanted preadipose tissue. Virchows Archiv B Cell Path 31: 143-155.

6) Kawaguchi N, Toriyama K, Nicodemou-Lena E, Inou K, Torii S, Kitagawa Y. 1998. De novo adipogenesis in mice at the site of injection of basement membrane and basic fibroblast growth factor. Proc Natl Acad Sci USA 95: 1062-1066.

7) Nicholls DG, Cunningham SA, Rial E. 1986. The bioenergetic mechanisms of brown adipose tissue thermogenesis. In: Brown Adipose Tissue (Trayhurn P, Nicholls DG, eds) p 52-85. Edward Arnold Publishers, London.

8) Ricquier D, Fleury C, Larose M. 1999. Contributions of studies on uncoupling proteins to research on metabolic diseases. Intern Med 245: 637-642.

9) Samec S, Seydoux J, Dulloo AG. 1998. Role of UCP homologs in skeletal-muscles and brown adipose tissuemediators of thermogenesis or regulators of lipids as fuel substrate. FASEB J 12: 715-724.

10) Clapham JC, Arch JR, Chapman H, Haynes A, Lister C, Moore GB, Piercy V, Carter SA, Lehner I, Smith SA, Beeley LJ, Godden RJ, Herrity N, Skehel M, Changani KK, Hockings PD, Reid DG, Squires SM, Hatcher J, Trail B, Latcham J, Rastan S, Harper AJ, Cadenas S, Buckingham JA, Brand MD, Abuin A. 2000. Mice overexpressing human uncoupling protein-3 in skeletal muscle are hyperphagic and lean. Nature 406: 415-418.

11) Ailhaud G, Negrel R, Glimaldi P. 1992. Cellular and molecular aspects of adipose tissue development. Ann Rev Nutr 12: 207-233.

12) Wassermann F. 1965. The development of adipose tissue. In: Handbook of Physiology. Section 5: Adipose tissue, p 87-100, American Physiological Society, New
York.

13) Shimazaki T. 1976. Pathology of chronic depressed marrow. Nippon Byori Gakkaishi 65: 27-31 (in Japanese).

14) Zucker-Franklin D, Grusky G, Marcus A. 1978. Transformation of monocytes into "Fat" cells. Lab Invest 38: $620-628$.

15) Harigaya K, Cronkite EP, Miller ME, Shadduck RK. 1981. Murine bone marrow cell line producing colonystimulating factor. Proc Natl Acad Sci USA 78: 6963-6966.

16) Sakaguchi K, Morita I, Murota S. 2000. Relationship between the ability to support differentiation of osteoclast-like cells and adipogenesis in murine stromal cells derived from bone marrow. Prostaglandins Leukot Essent Fatty Acids 62: 319-327.

17) Shigematsu M, Watanabe H, Sugihara H. 1999. Proliferation and differentiation of unilocular fat cells in the bone marrow. Cell Struct Funct 24: 89-100.

18) Greenwood MRC, Hirsh J. 1974. Postnatal development of adipose tissue cellularity in the normal rat. J Lipid Res 15: 474-483.

19) Cushman SW, Salans LB. 1978. Determination of adipose tissue cell size and number in the suspensions of isolated rat and human adipose cells. J Lipid Res 19: 269-273.

20) Bertrand HA, Lynd FT, Masoro EJ, Yu BP. 1980. Changes in adipose mass and cellularity through the adult life of rat fed ad libitum or a life-prolonging restricted diet. J Gerintol 35: 827-835.

21) Oscai LB, Miller WC, Arnall DA. 1987. Effects of dietary sugar and of dietary fat on food intake and body fat content in rats. Growth 51: 64-73.

22) Bertrand HA, Masaro EJ, Yu BP. 1978. Increasing adipocyte number as the basis for perirenal depot growth in adult rats. Science 201: 1234-1235.

23) Faust IM, Johnson PR, Stern JS, Hirsh J. 1978. Diet-induced adipocyte number increase in adult rats: a new model of obesity. Am J Physiol 235: E279-E286.

24) Sugihara H, Yonemitsu N, Miyabara S, Yun K. 1986. Primary cultures of unilocular fat cells: characteristics of growth in vitro and changes in differentiation properties. Differentiation 31: 42-49.

25) Sugihara H, Yonemitsu N, Toda S, Funatsumaru S, Watanabe K. 1997. Proliferation of small fat cells derived from unilocular fat cells of rats in collagen gel matrix culture. Acta Histochem Cytochem 30: 63-76.

26) Kawada T, Aoki N, Sugimoto E. 1991. Regulation of preadipocyte proliferation and a growth factor. In: Obesity: Dietary Factors and Control (Romsos DR, Himms-Hagen J, Suzuki M, eds) Japan Scientific Society Press and Karger, Tokyo and Basel.

27) Aoki N, Kawada T, Umeyama T, Sugimoto E. 1990. Protein factor obtained from rat adipose tissue specifically permits the proliferation of the 3T3-L1 and Ob1771 cell lines. Biochem Biophys Res Commun 171: 905-912.

28) Aoki N, Kawada T, Sugimoto E. 1993. Level of preadipocyte growth factor in rat adipose tissue which specifically permits the proliferation of preadipocytes is affected by restricted energy intake. Obesity Res $\mathbf{1}$ : 126-131.

29) Cornelius P, MacDougald A, Lane MD. 1994. Regulation of adipocyte development. Ann Rev Nutr 14: 99-129. 
30) Wu Z, Xie Y, Bucher MR. 1995. Conditional ectopic expression of $\mathrm{C} / \mathrm{EBP} \beta$ in NIH-3T3 cells induces PPAR $\gamma$ and stimulates adipogenesis. Genes Dev 9: 2350-2363.

31) Tanaka T, Yoshida N, Kishimoto T, Akira S. 1997. Defective adipocyte differentiation in mice lacking the C/EBP $\beta$ and/or C/EBP $\delta$ gene. EMBO J 15: 7432-7443.

32) Issemann I, Green S. 1990. Activation of a member of the steroid hormone receptor superfamily by peroxisome proliferator. Nature 347: 645-650.

33) Braissant O, Foutelle F, Scotto C, Wahli W. 1996. Differential expression of peroxisome proliferator-activated receptors (PPARs): Tissue distribution of PPAR- $\alpha$, $-\beta$, and $-\gamma$ in the adult rat. Endocrinology 137: 354 366.

34) Tontonoz P, Hu E, Graves RA, Budavori AI, Spiegelman BM. 1994. mPPAR $\gamma 2$ : tissue-specific regulator of an adipocyte enhancer. Genes Dev 8: 1224-1234.

35) Fajas L, Schoonjans K, Gelman L, Kim JB, Najib J, Martin G, Fruchart JC, Briggs M, Spiegelman BM, Auwerx J. 1999. Regulation of peroxisome proliferatoractivated receptor gamma expression by adipocyte differentiation and determination factor 1 /sterol regulatory element binding protein 1: implications for adipocyte differentiation and metabolism. Mol Cell Biol 19: $5495-5503$.

36) Kliewer SA, Umesono K, Noonan DJ, Heyman RA, Evans RM. 1992. Convergence of 9-cis retinoic acid and peroxisome proliferator signaling pathways through heterodimer formation of their receptors. Nature 358: 771-774.

37) Tong Q, Dalgin G, Xu H, Ting C, Leiden J, Hotamisligil G. 2000. Function of GATA transcription factors in preadipocyte-adipocyte transition. Science 290: 134-138.

38) Weiss MJ, Orkin SH. 1995. GATA transcription factors: key regulators of hematopoiesis. Exp Hematol 23: 99-107.

39) Hiragun A, Sato M, Mitsui H. 1988. Preadipocyte differentiation in vitro: identification of a highly active adipogenic agent. J Cell Physiol 134: 124-130.

40) Lehmann JM, Noore LB, Smith-Oliver TA. 1995. An antidiabetic thiazolidinedione is a high affinity ligand for peroxisome proliferator-activated receptor $\gamma(\operatorname{PPAR} \gamma)$. J Biol Chem 270: 12953-12956.

41) Forman BM, Tontonoz P, Chen J. 1995. 15-Deoxy- $\Delta$ 12,14 -prostaglandin $\mathrm{J} 2$ is a ligand for the adipocyte determination factor PPAR $\gamma$. Cell 83: 803-812.

42) Kliewer SA, Lenhard JM, Willson TM. 1995. A prostaglandin $\mathrm{J} 2$ metabolite binds peroxisome proliferator-activated receptor $\gamma$ and promotes adipocyte differentiation. Cell 83: 813-819.

43) Torii S-I, Kawada T, Matsuda K, Matsui T, Ishihara T, Yano H. 1998. Thiazolidinedione induces the adipose differentiation of fibroblast-like cells resident within bovine skeletal muscle. Cell Biol Int 22: 421-427.

44) Yu K, Bayona W, Kallen CB, Harding HP, Ravera CP, McMahon G, Brown M, Lazar MA. 1995. Differential activation of peroxisome proliferator-activated receptors by eicosanoids. J Biol Chem 270: 23975-23983.

45) Nagy L, Tontonoz P, Alvarez JA, Chen H, Evans RM. 1998. Oxidized LDL regulates macrophage gene expression through ligand activation $\operatorname{PPAR} \gamma$. Cell 93: 229-240.

46) Kawada T. 1996. Adipocyte differentiation and PPARcoactivator system. Mol Med 33: 1116-1124 (in
Japanese).

47) Okuno A, Tamemoto H, Tobe K, Kadowaki T. 1998. Troglitazone increases the number of small adipocytes without the change of white adipose tissue mass in obese Zucker rats. J Clin Invest 101: 1354-1361.

48) Kubota N, Terauchi Y, Miki H, Tamemoto H, Yamauchi T, Komeda K, Satoh S, Nakano R, Ishii C, Sugiyama T, Eto K, Tsubamoto Y, Okuno A, Murakami K, Sekihara H, Hasegawa G, Naito M, Toyoshima Y, Tanaka S, Shiota K, Kitamura T, Fujita T, Ezaki O, Aizawa S, Kadowaki T. 1999. PPAR gamma mediates high-fat diet-induced adipocyte hypertrophy and insulin resistance. Mol Cell 4: 597-609.

49) Forman BM, Chen J, Evans RM. 1997. Hyperlipidemic drugs, polyunsaturated fatty acids, and eicosanoids are ligands for peroxisome proliferator-activated receptors $\alpha$ and $\delta$. Proc Natl Acad Sci USA 94: 4312-4317.

50) Kliewer SA, Sundseth SS, Jones SA, Brown PJ, Wisely GB, Koble CS, Devchand P, Wahli W, Willson TM, Lenhard JM, Lehmann JM. 1997. Fatty acids and eicosanoids regulate gene expression through direct interactions with peroxisome proliferator-activated receptors $\alpha$ and $\gamma$. Proc Natl Acad Sci USA 94: 4318-4323.

51) Hida Y, Kawada T, Kayahashi S, Ishihara T, Fushiki T. 1998. Counteraction of retinoic acid and 1,25-dihydroxyvitamin $\mathrm{D}_{3}$ on up-regulation of adipocyte differentiation with PPAR $\gamma$ ligand, an antidiabetic thiazolidinedione, in 3T3-L1 cells. Life Sci 62: PL205-PL211.

52) Vidal-Puig A, Jimene ZM, Lowell BB, Hamann A, Hu E, Spiegelman B, Flier JS, Moller DE. 1996. Regulation of PPAR $\gamma$ gene expression by nutrition and obesity in rodents. J Clin Invest 97: 2553-2561.

53) Kawada T, Kamei Y, Sugimoto E. 1996. The possibility of active form of vitamins $\mathrm{A}$ and $\mathrm{D}$ as suppressors on adipocyte development via ligand-dependent transcriptional regulators. Int J Obesity 20: S52-S57.

54) $\mathrm{Hu}$ E, Kim JB, Starraf P, Spiegelman B. 1996. Inhibition of adipogenesis through MAP kinase-mediated phosphorylation of PPAR $\gamma$. Science 274: 2100-2103.

55) Adams M, Reginato MJ, Shao D, Chatterjee VH. 1997. Transcriptional activation by peroxisome proliferatoractivated receptor $\gamma$ is inhibited by phosphorylation at a consensus mitogn-activated protein kinase site. J Biol Chem 272: 5128-5132.

56) Zhang B, Berger J, Zhou G, Elbrecht A, Biswas S, WhiteCarrington S, Szalkowski D, Moller DE. 1996. Insulinand mitogen-activated protein kinase-mediated phosphorylation and activation of peroxisome proliferatoractivated receptor gamma. $J$ Biol Chem 271: 31771-31774.

57) Beamer BA, Yen C-J, Anderson RE, Muller D, Elahi D, Cheskin LJ, Andres R, Roth J, Shuldiner AR. 1998. Association of the Pro12Ala variant in the peroxisome proliferator-activated receptor-gamma2 gene with obesity in two Caucasian populations. Diabetes 47: 1806-1808.

58) Ristow M, Muller-Wieland D, Pfeiffer A, Krone W, Kahn CR. 1998. Obesity associated with a mutation in a genetic regulator of adipocyte differentiation. $N$ Engl $J$ Med 339: 953-959.

59) Barroso I, Gurnell M, Crowley VE, Aqostini M, Schwabe JW, Soos MA, Maslen GL, Williams TD, Lewis H, Schafer AJ, Chatterjee VK, O'Rahilly S. 1999. Dominant negative mutations in human PPARgamma associated with severe insulin resistance, diabetes mellitus and hyper- 
tension. Nature 402: 880-883.

60) Tontonoz P, Kim JB, Graves RA, Spiegelman BM. 1993. ADD1: a novel helix-loop-helix transcription factor associated with adipocyte determination and differentiation. Mol Cell Biol 13: 4753-4759.

61) Kim JB, Wright HM, Wright M, Spiegelman BM. 1998. ADD1/SREBP1 activates PPARgamma through the production of endogenous ligand. Proc Natl Acad Sci USA 95: 4333-4337.

62) Shimomura I, Hammer RE, Richardson AJ, Ikemoto $S$, Bashmakov Y, Goldstein JL, Brown MS. 1998. Insulin resistance and diabetes mellitus in transgenic mice expressing nuclear SREBP-1c in adipose tissue: model for congenital generalized lipodystrophy. Genes Dev 12: 3182-3194.

63) Shimomura I, Hammer RE, Ikemoto S, Brown MS, Goldstein JL. 1999. Leptin reverses insulin resistance and diabetes mellitus in mice with congenital lipodystrophy. Nature 401: 73-76.

64) Kamei Y, Xu L, Heinzel T, Torchia J, Kurokawa R, Glass B, Lin SC, Heyman RA, Rose DW, Glass CK, Rosenfeld MG. 1996. A CBP integrator complex mediates transcriptional activation and AP-1 inhibition by nuclear receptors. Cell 85: 403-414.

65) Janknecht R, Hunter T. 1996. A growing coactivator network. Nature 383: 22-23.

66) Mizukami J, Taniguchi T. 1997. The antidiabetic agent thiazolidinedione stimulates the interaction between PPAR $\gamma$ and CBP. Biochem Biophys Res Commun 240: 61-64.

67) Castillo G, Brun RP, Rosenfield JK, Hauser S, Park CW, Troy AE, Wright ME, Spiegelman BM. 1999. An adipogenic cofactor bound by the differentiation domain of PPARgamma. EMBO J 18: 3676-3687.

68) Kodera Y, Takeyama K-I, Murayama A, Suzawa M, Masuhiro Y, Kato S. 2000. Ligand-type specific interactions of peroxisome proliferator-activated receptor gamma with transcriptional coactivators. $J$ Biol Chem 275: 33201-33204.

69) Puigserver P, Wu Z, Park CW, Graves R, Wright M, Spiegelman BM. 1998. A cold-inducible coactivator of nuclear receptors linked to adaptive thermogenesis. Cell 92: 829-839.

70) Kawada T. 1998. PPAR-CBP and adipocyte differentiation. Diabetes J 26: 1-9 (in Japanese).

71) Dani C, Smith AG, Dessolin S, Leroy P, Staccini L, Villageois P, Darimont C, Ailhaud G. 1997. Differentiation of embryonic stem cells into adipocytes in vitro. J Cell Sci 110: 1279-1285.

72) Irie Y, Asano A, Canas X, Nikami H, Aizawa S-I, Saito M. 1999. Immortal brown adipocytes from $p 53$-knockout mice: Differentiation and expression of uncoupling proteins. Biochem Biophys Res Commun 255: 221-225. 